\title{
Seeing as Making: \\ Mediation, Rhetoric, and the \\ Ultrasound Informed Consent Act
}

Scott Weedon

Texas Tech University

Lubbock, TX

Poroi 16,2 (December 2021)

\begin{abstract}
How do material and discursive arrangements, technologies and rhetoric, shape the subjects and objects of medical discourse (Scott \& Melonçon, 2017; Selzer \& Crowley, 1999)? How are the affordances of material and discursive arrangements seized by political actors? Tackling these and similar questions has been a growing preoccupation in the rhetoric of science, technology, and medicine, where researchers have sought better ways of understanding the entanglements of the symbolic and material (Booher \& Jung, 2018; Graham, 2009; Jack, 2019; Propen, 2018). A perspicuous case for this research is the Ultrasound Informed Consent Act (UICA), an amendment to the Public Health Service Act mandating that women receive an ultrasound and have its images described to them before having abortions. Three US states have a version of this law, with over twenty others having laws similar to the UICA (Guttmacher Institute, 2019, n.d.). Through this law, antiabortionists are able to construct a kairotic situation through the mediating capacity of ultrasound where they can use the actual state of affairs (a woman seeking an abortion) to argue through images for a possible future (a woman foregoing abortion). This article analyzes the UICA to understand how the political speech of antiabortionists enrolls the moralizing capacity of ultrasound to construct a kairotic situation to intervene in women's pregnancies. Starting from studies of actor-networks (Latour, 1983;1999a) and technological mediation (Verbeek, 2011; 2015), and departing to feminist rhetorical science studies (Booher \& Jung, 2018; Frost \& Haas, 2017) and rhetorical approaches to imagery and visualization (Propen, 2018; Roby, 2016; Webb, 2009), I argue that not only do translation processes and technical mediation distribute agencies; they construct the very situations where agencies are constituted. This study can widen our understanding of how political entities appropriate the rhetorical capacities of technology and discourse to translate their politics into legislature.
\end{abstract}


Keywords: rhetoric of health and medicine, rhetoric of technology, kairos, visualization

In this article, I examine the rhetorical mediations of the Ultrasound Informed Consent Act (or UICA) to understand how the political speech of antiabortion activists enrolls the moralizing capacity of ultrasound to construct a kairotic situation to intervene in women's pregnancies ${ }^{1}$. The UICA is an amendment to the Public Health Service Act compelling providers to perform an ultrasound and describe its images to women before providing them abortions. Three US states have a version of this law, with over twenty others having laws similar to the UICA (Guttmacher Institute, 2019, n.d.). Through this law, anti-abortion activists are attempting to construct a kairotic situation through the mediating capacity of ultrasound where they can use the actual state of affairs (a woman seeking an abortion) to argue through fetal images and medical description for a possible future (a woman foregoing abortion). In attending to the assembling of the UICA and its material rhetoric, I trace the translation of political speech through imaging technology and medical description, and the rhetorical roles that mediating tools take on under the proposed law. Additionally, I suggest that through accounting for the rhetorical processes the proposed law would enact we are left with expanded conceptions of important elements of rhetorical theory, namely kairos and enargeia.

The impetus behind the project stems from Nathan Stormer's imperative for the rhetoric of health and medicine (RHM) to examine the discursive and material enactment of "prenatal space" as a means of controlling women's bodies (Stormer, 2000, p. 136). The analysis positions itself to account for the UICA's enactment of prenatal space by attending to "the mutual conditioning or interanimation of the discursive and material (e.g., forms of embodiment, technologies, objects) dimensions of health and medical practices, including what [N. Katherine] Hayles (1999) describes as a feedback loop between inscription and incorporation practices" (Scott \& Melonçon, 2017, p.6). The practices of antiabortion activists center on a constant and continuous production of discursive and material representations of the fetus and child in order to gain adherents to a stance against abortion (see Condit, 1990, chapter 5). Describing these rhetorical innovations and understanding the tactics they employ provides

\footnotetext{
${ }^{1}$ I use "women" here because the UICA specifically targets women in their text. Yet that does not preclude or exclude the fact that this Act would likely affect anyone with a uterus as well as hinder non-binary people's access to other types of healthcare. Often, abortion providers operate in facilities where many members of a community seek healthcare that they cannot otherwise access.
} 
rhetoricians of health and medicine with the means to develop critiques of these practices and competing conceptualizations.

I will firstly situate the UICA by describing its contents and its mediating capacities before discussing how the concept of kairos may help rhetoricians of health and medicine understand technology's role in the UICA. Then I will attend to the argumentative tactics of the act by recasting the UICA's directives as a type of ekphrasis. My goal is to chart the material and discursive enactments, the power of rhetorical technologies to body-forth political subjects, which equip the UICA with its rhetorical force.

The UICA is an amendment to the Public Health Service Act and a permutation of state and federal laws compelling healthcare providers to show women an ultrasound before having an abortion. It has been circulating in the House of Representatives since 2014 and was last proposed in January of 2019. While the UICA has not received a vote, it has slowly gained more and more sponsors, moving from less than a dozen to now over thirty.

The text of the UICA is as follows:

(a) Requirement Of Compliance By Providers. - Any abortion provider in or affecting interstate or foreign commerce, who knowingly performs any abortion, shall comply with the requirements of this title.

(b) Performance And Review Of Ultrasound. - Prior to a woman giving informed consent to having any part of an abortion performed, the abortion provider who is to perform the abortion, or an agent under the supervision of the provider,

shall -

(1) perform an obstetric ultrasound on the pregnant woman;

(2) provide a simultaneous explanation of what the ultrasound is depicting;

(3) display the ultrasound images so that the pregnant woman may view them; and

(4) provide a complete medical description of the ultrasound images, which shall include all of the following: the dimensions of the embryo or fetus, cardiac activity if present and visible, and the presence of external members and internal organs if present and viewable.

(c) Ability To Turn Eyes Away.-Nothing in this section shall be construed to prevent a pregnant woman from turning her eyes away from the ultrasound images required to be displayed and described to her. Neither the abortion provider nor the pregnant 
woman shall be subject to any penalty under this title if the pregnant woman declines to look at the displayed ultrasound images.

The UICA specifically utilizes the doctrine of informed consent in an attempt induce women to view an ultrasound image and hear a medical description of their uteruses in order to show them the state of their fetus and inform them about their choice to have an abortion. It is the ultrasound and description of the UICA's directives that constitute informed consent in antiabortionists' eyes (see Manian, 2009 for an overview of the history of informed consent and abortion from Roe on).

Antiabortionists use the Planned Parenthood of Southeastern Pennsylvania v. Casey ruling, and several subsequent cases, that allow states to mandate certain truthful and non-misleading information be given to a woman as long as it does not place an undue burden on a woman's right to abortion (Casey, 1992). The UICA extends the logic of the bill by arguing that mandating a woman to have an ultrasound and having the image described in medical detail is not an undue burden on her choice to have an abortion but is rather a necessary action for her to make an informed decision before choosing an abortion. The specific choice of the ultrasound and description rests on the perceived impact these images have on women. Sian M. Beynon-Jones and Lisa Mitchell's work has unpacked the logic of the ultrasound screening (Beynon-Jones, 2015; Mitchell, 2001). Showing ultrasound images to women is thought to persuade them to forego aborting their fetus because the images display a fetus that (through a healthcare provider's description) can show rudimentary features that may be ascribed to an infant, prompting a woman to identify and "bond" with the image. Ultrasound may show actions that can be glossed as volitional or infantile, thus investing the fetus with personhood (Mitchell, 2001; see also Stormer, 2000). Feminist and science studies research, such as Rosalind Petchesky's and Barbara Duden's foundational work, has troubled each of these claims by contesting ultrasound's power to change minds on abortion and critiquing narrative practices that invest the fetus with behaviors and nervous systems characteristic of children (Duden, 1993; Petchesky, 1987).

In the feminist, antiracist, and STS literature on reproductive technologies and policies, the power of ultrasound images to foreground and establish the personhood of the fetus while erasing the female body from view has been thoroughly researched and theorized for decades. The widely cited work of Petchesky demonstrates how the popular image of the fetus is cut off from its environment, namely the woman's womb, through particular technological means of photography and obstetric ultrasound. In Karen Newman's history of fetal representation, the 
erasure of the woman's body and distinctiveness of the fetus as sovereign entity has a history in medical images and models showing the fetus as a fully formed child from conception (Newman, 1996). This separation is part of the routine work of prenatal care, where obstetric ultrasound is used to figure the fetus as distinct from the mother and imbue it with childlike features (Mitchell, 2001). Karen Barad, Monica Casper, and Peter-Paul Verbeek have all argued that the fetus is enacted as child, patient, or fetal tissue through technologies and practice, and these enactments are taken up as commonplaces that organize how topics such as life may be understood (Barad, 1998; Casper, 1994; Verbeek, 2011; see also Rowlands, 2017 and Stormer, 2008 for the circulation of topoi of human reproduction). The critique of abortion access from Dorothy Roberts situates the struggle over abortion access and its attendant imagery as only one element in a suite of political strategies to disenfranchise and criminalize Black motherhood (Roberts, [1997] 2017).

Recent rhetorical explorations of using ultrasound to display women's wombs have highlighted the persuasive force of its images. Rochelle Gregory argues that ultrasound images in bills like the UICA trade on the iconic status of the fetal image to promote woman to identify the image of their fetus with an image for life (Gregory, 2012). Erin A. Frost and Angela M. Haas offer a technoscientific feminist approach to examine how an uncritical uptake of technologies that open women's bodies to view leave those same bodies open to exploitation (Frost \& Haas, 2017). Amanda Nell Edgar provides a case study of this kind of exploitation in detailing the ways a woman's corporality is rhetorical when it is tuned as an amplifying technology for a fetus's heartbeat (Edgar, 2017). Finally, in a response to a Texas bill similar to the UICA, Amy Koerber, Amanda Booher, and Rebecca Rickly critique the concept of informed consent for decisionmaking that anchors the necessity for the bill (Koerber, Booher, \& Rickly, 2012). They note the bill mandates a woman to be present for the display and description of the image before they seek an abortion, conveying the idea that women lack knowledge and understanding of their choice and need a legislature to inform them on their own bodies. They conclude that rather than promoting choice, bills like the UICA do as much as they can to constrain it.

These studies outline the layered rhetorical forces that frame the ultrasound image in bills like the UICA. These laws however are not the product of the unadulterated force of political will, but instead, the process of gathering together many different allies to create power. Edgar notes that the rhetoric of fetal heartbeat and speech and display laws like the UICA is thoroughly forceful and fluid, and like a river's tributaries, carves out new networks of 
association, strengthening and spreading a rhetoric's effects and affects (Edgar, 2017, p. 365). Tracing the relations among actors of the UICA helps to shed light on how these actors gather and mobilize power, and the following section will start with an analytical terminology inspired by Actor Network Theory (ANT) to do just that (Gruber, 2014; Latour, 1999a). ANT analysis has become popular in rhetorical studies for being particularly useful for showing how objects gather or are gathered into associations and translated from context to context (Graham, 2009; Kessler \& Graham, 2019; Walker, 2016). Bruno Latour models network analysis by showing the transformations and translations scientific data undergo in becoming facts (Latour, 1983; 1999). This work of accounting for the different transformations phenomena undergo in their association with technologies and situations allows us to see how policies like the UICA rely on a host of heterogeneous actors to be made actual and effective. Yet, as revealing as this perspective can be, the analysis still needs to go further than the tracing of a powerful network, and account for the immediate rhetorical effects the UICA is designed to produce for women. Thus, there is a need for analytical tools that attend to the orchestration of that experience to understand the kind of situation being set up by the UICA, how that situation is constituted (by both human and nonhuman actors), and how identities like child and fetus are rhetorically designated and stabilized. To meet these needs, I will abbreviate my ANT-inspired approach tracing the composition of the UICA to complement it with a rhetorical analysis of the discursive-material apparatuses deployed to mediate women's experiences and configure the category of the child. Rather than applying an overarching framework or performing theory to situate the UICA, I look for explanatory concepts that bring certain crucial elements of the UICA into focus. This approach will be methodologically messy, as Rebecca Rickly might term it; however, the hope is that such a mess can better highlight the various rhetorical tactics the UICA employs to restrict access to abortion (Rickly, 2007).

\section{The Constitution and Mobilization of the UICA}

The UICA and earlier, similar laws, form through the confluence of think tanks, technologies, court precedents, and legislatures. Americans United for Life, a think tank for antiabortion advocacy, provides model laws which legislatures use to craft their own laws. These laws enroll the U.S Supreme Court's Planned Parenthood $v$. Casey, 505 U.S. 833 decision as grounds to argue for several things, principal of which is a state's interest in carrying fetuses to term 
and the need for informed consent in abortion procedures (Casey 1992; Suter, 2015). While the Casey decision allowed the distribution of written materials steering women away from aborting their fetuses, several current laws have enrolled ultrasound technology to make their argument. In laws such as the UICA, the determination of the viability of the fetus and its communicability is mediated through imaging technology and medical description. The aims of antiabortionists are modified in the alliance with ultrasound and medical description; politics become biopolitical, conjoining a perspective on life with techniques for representing and describing life at a particular moment in time. Imaging ultrasound technology's persuasive power rests on the cultural significance of the fetus and more fundamentally on the black-boxed notion of what S. Scott Graham calls ocular-centrism (Graham, 2009; Gregory, 2012). Ocular centrism warrants many beliefs, but in this context, it refers to the axiom that images can stand in for the thing itself; images constituted through sound waves offers a window into the womb, circumscribing the fetus from the woman. The ocular-centrism of ultrasound elides the history, science, and the practices that both Karen Barad and Kelly Joyce argue stabilize its function and turn the highly rendered image of the fetus into a real-time video of a potential child (Barad, 1998; Joyce, 2005).

However, ultrasound is not only authoritative because of its foundation upon ocular centrism but also due to its routine use for representing fetuses. Like other imaging technologies, it has unquestioned standing in typical medical situations and is a fixture of the medical surveillance of pregnancy (see Frost \& Haas, 2017 and Mitchell, 2001 for discussions of the routine use of ultrasound during pregnancies). Ultrasound has a generic function as it acts as an agent in medical scenes of pregnancy with an agency of providing information on fetuses, and this agency is easily appropriated by the UICA into their own scenes of informed consent. The UICA's arrangement of these elements accrues authority through the typicality of the situation it cites; that is, because ultrasound is part of the furniture of routine medical encounters with pregnancy, its elaboration to a site of informed consent is framed as natural and becomes an "obligatory passage point" in the process (Latour, 1999a, p.184). In Erin A. Frost and Angela M. Haas's terms, ultrasound has "colonized" the woman's pregnant body, and thus licensed future technological incursion and surveillance (Frost \& Haas, 2017).

Ultrasound technology is one aspect of the UICA, which gathers many heterogeneous actors together such as legislatures, medical protocols, consumerist approaches to medicine, religious beliefs, and much more. The potential of the gathering of these 
elements is revealed through the text of the UICA as it "locks" the various elements (informed consent, ultrasounds, medical description, healthcare providers) into a unified rhetorical force by defining their roles (Callon, 1984, p. 196). For instance, the ultrasound's depiction is equated with the fetus and not the woman's womb, in effect eliding the woman's body. This elision is quite fluid, however, as the depiction is used to inform the woman of a procedure she will have on her own body while simultaneously informing her that it is not her own body that is undergoing this procedure, but a separate body of fetus and potential child with discrete dimensions and human attributes (more on this dynamic below). The woman's body shifts in identity and priority through the sequence of the consultation, arranged by the text of the UICA.

The text also accomplishes what Celeste Condit, following Kenneth Burke, calls a "casuistic stretching", or the stretching of a term into new conceptual territory, by having the genre of informed consent equated with the invasive procedures for which women have no choice but to consent to if they want an abortion (Condit, 2007, p. 240). Informed consent and its routine placement in medical consultations is used to warrant extracting information from women that they have no choice but to give. The enrollment of informed consent is particularly important, because as stated above, it recruits the judicial power of the Casey decision, providing antiabortionists an opportunity to promote their interests through channels of policy. Through this alignment, the political speech of the antiabortionist is allowed to be translated into legislative terms and mobilized by legislators who then perform rhetorical demonstrations amplifying the rhetorical force of laws like the UICA (see Edgar, 2017, for fetal heartbeat demonstrations in legislatures).

These various elements (technologies, lobbyists, legislature, medical procedures, and culturally iconic images) are collected, manifested and provided rhetorical force through the text of the UICA. David Gruber argues that texts bring heterogeneous actors and the traces of the situations they constitute together while simultaneously occluding the presence of some actors, thus making visible a particular meaningful arrangement of associations (Gruber, 2014; see also Read, 2016 for an understanding of how genres function in networks and bracket actors for social action). While the UICA is the work and coordination of many human and non-human actors, the text makes visible only a few and shapes its uptake through what it reveals.

Translation of the UICA proceeds by linking thinktanks, ultrasound, legislatures, and laws with genres such as informed consent, medical consultations, medical description to mediate and materialize political speech. It should be noted that this process was 
a long one and is the work of a long history. The text, its elements, and its shaping is not a linear composition. The rhetorical work of aligning the fetus with the child through images and aligning informed consent with compelling women to know about their fetuses is extensive (see Ahmed, 2015; Sanger, 2008; Suter, 2015). Thus, in order to see how these rhetorical forces suddenly gain traction with a public we must be both aware of the history of rhetorical positioning, and as Segal has shown, the kairotic moments where that positioning coincides with opportunities to be mobilized (Segal, 2005).

This abbreviated analysis of translation shows that the association of these different actants come together through a mix of affordances and kairotic moments. Antiabortion activists seize upon an opportunity that was opened up the confluence of judicial precedent and the affordances of imaging technology in order to mediate their argument. This is not to say that the UICA and similar acts are transparent conveyances for antiabortionists' preconceived notions. Rather, the argumentative ground for antiabortionist claims shifts and transforms in order to take advantage of opportunities in laws for informed consent, states' biopolitical prerogatives, and imaging technologies' rendering capacities.

\section{Mediation, Morality, and Rhetoric}

I now want to shift analysis from the gathering, translating, and mobilization of actors to the rhetorical experience they effect. I focus particularly on the affordances of ultrasound technology and the rhetorical power of medical description to understand the role of kairos and enargeia in the UICA. ANT perspectives on translation and mediation are exceptionally helpful in order to understand the entanglements of elements that constitute kairotic moments; in this case, the elements of scientific and medical policy enaction. However, a singular focus on tracing networks can leave some analyses attenuated. Assembling actors and their associations can leave out the rhetorical texture of action. Furthermore, as Jen Talbot has recently shown in a discussion of a North Carolina law similar to the UICA, the ANT injunction to treat all the elements of a network as agents can end up cutting the fetus off from the agency and experience of the mother (Talbot, 2018). Talbot suggests adopting approaches that foreground the embodied experience of mothers and the rhetorical practices that segment and produce agents and identities. Indeed, rhetoric scholars often complement ANT-inspired analyses with rhetorical theory in order to capture 
the deliberative and persuasive possibilities of networks (e.g. Graham, 2009; Gruber, 2014; Walker, 2016). Furthermore, such a focus can fulfill the promise of ANT to offer an ethnomethodological account of actors' world-building practices (Latour, 1999b, pp. 19-20). While ANT has unquestioned utility for tracing the human and nonhuman actants mediating phenomena, I suggest that for a more textured understanding of any these actants, whether the particular affordances of tools, the appropriation of these affordances by human beings, or, as Casper notes, the practical and rhetorical activity that mediates the designations of human and nonhuman in the first place, we need recourse to other approaches (Casper, 1994, p. 308).

I want to then start with insights from the philosophy of technology, move to the study of kairos in rhetorical scholarship, and then put the resulting concept of a technological kairos into conversation with feminist rhetorical studies of science and medicine. I first turn to recent work in the philosophy of technology that has theorized the moral agency of technologies, claiming technologies mediate how the world is experienced, and how they thus bring forth questions of morality where none would be present otherwise.

Approaching the subject from a Dutch context, Peter-Paul Verbeek unravels ultrasound's ability to represent a pregnant woman's uterus and establish hermeneutic and material relations between what is represented and the technology's users (Verbeek 2008; 2011, chapter 2). He discusses the practice of routine prenatal screenings for Down syndrome and other genetic issues, to show how moral questions emerge from ultrasound's mediating ability to visualize signs of Down syndrome at an early stage in pregnancy. While he could have focused on any number of prenatal and pre-implantational tests, such as amniocentesis and chorionic villus sampling, and the host of moral questions stemming from screening fetuses, his focus remains on technologies that mediate human relations with the world and each other, and he considers how they partially constitute the roles participants may take in given situations. Ultrasound, for instance, "constitutes the unborn in a very specific way: it helps to shape how the unborn can be perceptually present, and how it can be interpreted on the basis of the specific ways it is represented" (Verbeek, 2008, p.15). For the pregnant woman and ostensibly her partner, ultrasound shapes them into decision-makers (if the ultrasound is performed at the appropriate gestational stage), possibly having to decide whether to bring a fetus to term if the ultrasound detects issues that would impact the quality of future life for the child- or parents-to-be (Verbeek, 2011, p. 26). These roles and the very shape of the situation where they arise are mediated by the technological 
affordances of ultrasound, which constitutes the participants into moral subjects.

I suggest that to understand the rhetorical power of the UICA in particular, we must think through technology's power to position moral subjects and open up kairotic moments. To achieve this aim, I bring together a recognition of technology's capacity to shape the agency of users with the rhetorical concept of kairos.

The mediational power of ultrasound and other technologies can serve as a kind of kairos, or a conjunction of the opportune moment and the possible. Kairos shapes a situation (Poulakos, 1983); or in Carolyn Miller's characterization kairos names: "the particular opportunity in a given moment, to find-or construct-an opening in the here and now, in order to achieve something there and then" (Miller, 1994, p. 83). Kairos as it relates to rhetoric is a matter of both the appropriate style for a particular audience and what they could possibly be persuaded of, adhere to, or emotionally resonate with. Recent rhetorical theory has emphasized not only the temporal and discursive aspects of kairos, but also its spatial and material aspects, as well (Rickert, 2013; Walsh \& Boyle, 2017). Kairos is not only a matter of a "semiautonomous, willing" rhetor's ability to seize the right moment; agencies are "condensations of probabilities, realized in movement, materialized in space, and invented in place (Rickert, 2013, p. 97). Kairos is a dynamic interplay between humans and the affordances of an environment that shape moments, "situating us in arrangements that simultaneously unleash some possibilities and foreclose others" (Rickert, 2013, p. 96).

While kairos may be thought of as an unforeseen happening that is unamenable to methodology or planning, Carolyn Miller shows that kairos can be created through discourse that structures a future opening in the present for (say) a technological breakthrough (Miller, 1994). Discourse as technology forecasting, talk of technological, military, or aerospace gaps between companies or countries, or (the end of) Moore's law are all kairotic strategies that use present knowledge and resources to predict and construct future moments for establishing technological advancements beyond present needs. Miller describes this feature of kairos as "function[ing] as a constructive power: one has the opportunity to make an opportunity at any time, from situational resources that can be constructed in a variety of ways" (Miller, 1994, p. 83). Miller's focus on the rhetorical construction of technology is key to understanding the function of ultrasound in the UICA, and yet, it is also important to keep in mind the potential of technologies to encourage, arrange, and ground ways of doing and being that in turn will condition the possibilities of a kairotic moment. 
I want to emphasize not only discourse's capacity to construct kairotic opportunities, but also, technology's capacity to structure kairos through its affordances. Following from the expanded conceptions of kairos above, I want to move back to the affordances of ultrasound and suggest the UICA uses ultrasound technology to control a moment opened by judicial precedent and technological affordance to construct a rhetorical situation. This is a strategy that is both material and discursive, arranged rather than just seized, and relying on the technical/medical environment as much as human agency. In simpler terms, the situation of a woman subject to the UICA and similar laws allows antiabortion advocates to induce a woman's deliberation about whether to bring the fetus to term through witnessing its exhibition. To quote Americans United for Life: “The knowledgeable exercise of a woman's decision to have an abortion depends on the extent to which she receives sufficient information to make an informed choice between two alternatives: giving birth or having an abortion" (2019, n.d.) This deliberative situation is orchestrated through technological mediation, epideictic rhetoric, and legislation.

In the UICA and similar laws, ultrasound imagistically provides a rhetorical opening, where a fetus enlivened with anatomical description, promotes the choice of not having an abortion. Material-discursive networks like those that comprise the UICA facilitate deliberative spaces by inserting a particular technological mediation into a situation. In the case of having an abortion under laws like the UICA, ultrasound's affordance of imaging opens up a deliberative moment by positioning the woman as a decision-maker receiving information. However, Koerber, Booher, and Rickly remind us that speech and display laws like the UICA do not actually offer women a choice, despite the fact that the consultation is structured as a deliberative situation (Koerber, Booher, \& Rickly, 2012). Instead, the UICA uses ultrasound images and medical description to position the woman as a witness to the revealing of her potential child, to exhibit a life that, in antiabortionists' eyes, should be saved. The kairotic moment I am isolating is not the woman's but antiabortion advocates': it is an opportunity opened by the technological affordances of ultrasound for antiabortion advocates to argue through images for bringing the fetus to term. This kairos is created as a rhetorical positioning and mediating capacity of imaging technology to create moral situations by casting participants as decision-makers of moral questions, which are themselves generated and shaped by technology (see Verbeek, 2011 for an extended analysis of ultrasound's mediating capacities). As we will see below, the ultrasound image and medical description constitute the bodily relations fetus and woman have to each other. However, these relations are not just bodily, but moral 
as well. Constituting the fetus as a child and the woman as a prospective mother is an attempt to instill some maternal responsibility in the woman. This is the thrust of the UICA's argument, and in its capacity as a law, institutes a perpetual opportunity, a chronic kairos, to make this argument against women's abortions.

In the conclusion, I will discuss the implications of a technologically mediated kairos for rhetorical theory. What remains to explore are the rhetorical strategies the UICA employs to make its case to women seeking abortions. Kinneavy notes that classical and modern understandings of kairos describe its epistemological character as "bring[ing] timeless ideas down into the human situations of historical time" (Kinneavy 2002, p. 62). In the case of the UICA, the (seemingly) timeless idea is in the form of the "culturally iconic sign" of the fetus as imaged by ultrasound that is "factual, positive, educational, and informative" (Gregory, 2012, n.d.). Gregory notes that laws like the UICA seek to use ultrasound to argue that early term fetuses should be seen as full-term 32-week fetuses. While many researchers have focused on the role of ultrasound in this process, as Verbeek emphasizes, it is important to understand the rhetorical interactions users have with, along, and through technological mediations (Verbeek, 2015). The UICA specifies a very particular rhetorical performance that facilitates transformation of the fetus into the child: the act states that a provider must perform an anatomical and physiological description of the imaged fetus. Furthermore, the force of this visual-verbal interaction rests principally on ocular-centrism and entails a litany of antiabortion assumptions, which I describe below.

In press releases, public hearings, YouTube videos, memes, and articles from the National Pro-Life Alliance and politicians, ultrasounds and accompanying medical description work to show women the actuality of the living and distinct fetus (Brownback, 2007; Jordan, 2012). Michael Stokes Paulsen, a professor of law at the University of St. Thomas, distills the approach of the UICA by writing that ultrasound "makes clear exactly" that the fetus is a "living" child "separate" from the woman (Paulsen, 2013; n.d.). The woman can "actually see" from the ultrasound image the "scientific fact" that the fetus is "a distinct human being." This "truthfulmedical" presentation "enlightens" the woman, providing "persuasive, emotional force" (that is legally "consistent with choice") for her to choose to not have an abortion. In the mind of antiabortionists, the procedure makes plainly visible a distinct human being inside the womb in order to enlighten the woman to choose to bring the fetus to term. The UICA mirrors Stormer's contention that "abortion is death only if we can see the embodied life in the womb" (Stormer 1997 p.174). I argue that this seeing is 
achieved through the visual-verbal interaction of describing an ultrasound image; it is a kind of ekphrasis, a rhetorical technique to make present an object or scene, or in this case, a child.

Contemporary discussions of ekphrasis often hail from poetics, art criticism and history, where ekphrasis is understood as an artist's attempt to render art or an artwork from one medium into another. But recent scholarship in the theory and history of rhetoric has recovered an alternative understanding of ekphrasis that establishes its primary function as "bringing an object before the eyes," to turn listeners into spectators and witnesses (Goldhill, 2007; Jarratt, 2019; Prasch, 2019; Roby, 2016; Webb, 2016). Unlike the modern understanding of ekphrasis of describing one artwork in the medium of another (which is, strictly speaking, only about fifty years old), earlier conceptions of ekphrasis were connected to the process of enargeia (making an object clear and vivid through description), and later, increasingly enfolded the distinct Aristotelean concept of energeia (vivifying or actualizing an image through discourse) (Webb, 2016). Ekphrasis was a distinct figure practiced in grammar schools in the ancient world and used in various arts and sciences (Roby, 2016). It is a figure of force rather than meaning that seeks to induce an audience to imagine as if the object displayed is present.

Enargeia, or making the absent present through vivid detail, is related, according to T. Kenny Fountain, to the latter-day rhetorical concept of presence, Chaim Perelman's description of a rhetor's selection of elements to foreground and thereby bring to an audience's attention (Fountain, 2019, p. 228; Perelman \& OlbrectsTyteca, 1969, p. 174). Presence was not and is not limited to the arts and oratory but is at work in forensic, technical, scientific, and medical contexts, as evidenced in a variety of research (Gross, 1990; Jack, 2009; Shapin, 1984; Teston, 2012; Weedon, 2017; but see Gross, 2017, pp. 8-10, for a differing perspective). The ancient practice of ekphrasis is a technique for an author or other entity to achieve presence for an audience.

According to Umberto Eco, ekphrasis is verbal description that produces enargeia by accumulating detail and making the absent present (Eco, 2004, pp.180-201). In speeches, poems, and forensic narratives, ekphrasis transports the listener through space and time, induces imagination, bounds cultural knowledge, turns an audience into spectators rather than simply listeners, and even enthralls listeners through vivid imagery According to Courtney Roby, in ancient scientific and technical contexts, ekphrasis would index perspectives or expertise, link artifacts to specific contexts, and weave various fields of knowledge together (Roby, 2016). While researchers have mined ancient and contemporary psychological theories to understand how ekphrasis can be said to achieve these 
effects, it is enough for our purposes here (and consistent with these sources) to say the figure invites or induces an audience to pretend to see a thing or mentally unfold an action (Hawhee, 2011; Prasch, 2019).

To get a better understanding of the ekphrasis and its relationship to scientific, and by extension, medical description, I turn to Lorraine Daston's recent juxtaposition of two passages in a discussion of description in cloud classification:

We habitually think of the rain-cloud only as dark and gray; not knowing that we owe to it perhaps the fairest, though not the most dazzling of the hues of heaven. Often in our English mornings, the rain-clouds in the dawn form soft level fields, which melt imperceptibly into the blue; or when of less extent, gather into apparent bars, crossing the sheets of broader cloud above; and all these bathed throughout in an unspeakable light of pure rose-color, and purple, and amber, and blue; not shining, but misty-soft; the barred masses, when seen nearer, composed of clusters or tresses of cloud, like floss silk; looking as if each knot were a little swathe or sheaf of lighted rain. No clouds form such skies, none are so tender, various, inimitable. Turner himself never caught them.

-Ruskin

7. Nimbus (Nb.), Rain Clouds. -A thick layer of dark clouds, without shape and with ragged edges, from which steady rain or snow usually falls.

- Atlas international des nuages (quoted in Daston, 2016, p.1).

Daston calls Ruskin's writing an ekphrasis, while the atlas's definition she characterizes as a terse description, the former, literary, and the latter, scientific. However, both passages are after the same thing, namely, to describe a particular and recurrent cloud formation. The routes they take to get there are different, however; ekphrasis unfolds detail upon detail to capture as much of the phenomenon as possible, to make it distinct and recognizable, while the atlas's description focuses solely on the distinct and recognizable features in order to frame the phenomenon as most importantly consisting of just the features mentioned. Daston suggests a further difference between ekphrasis and description, writing that, "[t]he goal of [scientific cloud description] was not mimesis or even vivacity, but rather truth to nature, what Ruskin called a 'truth of species' in art" (Daston, 2016, p. 11). While the difference may hold in the classification and identification of 
clouds, I will argue in other practices such as ultrasound imaging, mimesis, vivacity, and framing work together to make a phenomenon present.

Before I turn to that argument, I want to further explain the choice for calling this particular use of medical description ekphrasis. Ekphrasis may serve has a more precise description of what is proposed by the UICA than the more common terms for medical explanations of ultrasound, such as narration. While certain interactions between caregivers, pregnant women, and ultrasound images may be understood as acts of narrating, those verbal-visual interactions that seek to make the image vivid before the eyes of the pregnant woman may be more aptly understood as ekphrasis. Ekphrasis is working when the verbal-visual act accumulates perceptible detail and elaboration of the object or event (Webb, 2016, pp. 71-73). The UICA not only compels a provider to display images of the fetus and delineate it from the amniotic fluid and uterine lining, but to also provide a complete medical description of the images, including the dimension of the fetus or embryo, any cardiac activity, its appendages, and its organs, if visible. Showing and telling, narrating or describing, are not adequate to capture the dwelling-on and specifying prescribed by the UICA. The quality of ekphrasis that separates it from narration and contemporary understandings of description is its supposed ability to bring the thing detailed before the eyes of the listener. While theorists and classicists note ekphrasis relies on an audience's participation, there is an acknowledgement of ekphrasis's power, in the words of Longinus, to enthrall the listener by stirring the emotions (i.64).

This power of ultrasound description is recognized in arguments questioning the legality of laws like the UICA where displays of graphic imagery are challenged on the grounds that it prompts an emotional, persuasive, and irrational response, and thus may put undue pressure on, or even preclude the use of, an actor's rational choice (Sawicki, 2014). The prizing of rationality as the only trustworthy decision-making capacity may give rhetoricians pause, but the concern does highlight the effects of images and graphic speech. Ekphrasis is discourse that seeks to be like imagery and wield imagery's power.

Now, my focus turns to the dynamics of this powerful visualverbal interaction and how it helps to further understand the multilayered force of the UICA. Turning back to the UICA's directives, we see the bill would mandate providers to follow a precise procedure for ekphrasis in order to collapse the denotative and descriptive. The medical description overlays the ultrasound image to diagram, vivify and detail the fetus into the realm of the living and the distinct. In popular discourse, the ultrasound image is positioned as 
a window. In practice, an ultrasound technician will show views of the ultrasound translated soundwaves, using a cursor, finger, or other deictic device to pick out and describe features on the screen. While the images themselves are slices of the womb and do not offer detailed resolution of what is depicted, this picking out, measuring, and naming constitutes and brings before the eyes an embodied phenomenon delimited from the womb.

The medical description is not simply hermeneutic of the ultrasound image; it repositions the image into a space where the woman is to make imaginary contact with the fetus while simultaneously having it delineated from her body. The description as deployed by the UICA dwells on the image, repurposing the ultrasound image from its diagrammatic function of making the fetus mappable and diagnosable to collapsing the image into the potential child through medical description. The fetus is physiologically and anatomically re-inscribed as living and separate, thus rhetorically backgrounding the fetus as enwombed to make present a distinct entity more akin to that of a child. The UICA attempts to turn the woman into a spectator of the child in opposition to her embodied knowledge of the fetus, creating an immediacy with the image and an identification with its physiological and anatomical form while distancing the woman from what she actually sees: her womb. This dynamic is ekphrastic in that it brings forth an image to stand in for the thing itself while simultaneously using that image to re-inscribe what it represents in medical terminology, amplifying its personhood. It vivifies the fetus as it clarifies it for view, thus medically rendering it as distinct and living, and further linking it with a politics of fetal personhood. The UICA has achieved its aim by staging a type of medical theater to induce a change in aspect of a woman's uterus.

I want to highlight here a few significant dynamics of this rhetorical action. The visual-verbal interaction of ultrasound image and medical description adds a new element to the rhetorical technique of ekphrasis. Ekphrasis is traditionally understood in rhetorical theory as a technique for inducing enargeia, the action of bringing something before the eyes. Its function is to delineate and detail. Energeia, on the other hand, is a technique theorized by Aristotle for vivifying discourse, making the potential actual (Roundtree, 2013, pp. 37-38; see Westin, 2017 for a detailed discussion). It creates and enlivens objects and scenes. These two operations are conceptually distinct, but in the case of the UICA they are collapsed. The fetus is rhetorically positioned as a potential child through the medical construal of ultrasound images. The initial, un-explicated image brought forth, however, is indistinct and in need of detailed explanation. Through a medical description that delineates the fetus from the mother by accumulating 
anatomical and physiological details, the fetus receives the attributes of a child, actualizing the potential in the image through anatomical clarification. Thus, the medical description brings the child into a distinct and discrete life.

Monica Casper, Donna Haraway, and Karen Barad, among many others, have addressed the ways practices constitute what are often taken to be essential categories of gender, agency, or even the human (Barad, 1998; Casper, 1994; Haraway, 2004). By examining the rhetorical practices of the UICA, we can see how technology and description ekphrastically render and stabilize a fetus into a child. Ekphrasis provides a concept of how material-discursive apparatuses do the work of making phenomena present through the twin actions of vivification and clarification, actualization and delineation. While some recent research in rhetorical studies has analyzed the rhetorical force of technologies and objects themselves, the rhetorical potential of objects and technologies is often constituted by distinct human-object interactions in particular environments (Alac, 2011; Gouge and Jones, 2016; Henderson, 1999; Lynch \& Kinsella, 2013; Teston, 2012). How images and technologies are construed, segmented, and talked about shape what they do, and so to comprehend what technologies do and how they mediate action, we must continue to study "how humans give meaning to these mediations" when they are part of the action (Verbeek, 2015, p. 191, emphasis in original). By attending to the rhetorical positioning of the ultrasound image, we see that the UICA seeks to stabilize and control the meaning of the ultrasound image through a medical description that more than glosses and interprets the image; it brings it to life, makes it "real" and actual for the pregnant woman, and pushes the fetus into personhood.

In reviewing the rhetorical innovations of the UICA, we saw how the concept of kairos helps us understand how the UICA is enacted. By seeing in obstetric ultrasound a way to seize an opening made possible by judicial precedent and technological mediation, antiabortionists are able to construct a situation in which they are able to use the actual state of affairs (a woman seeking an abortion) to argue for a possible future (a woman foregoing abortion). They do this by taking the fetus-as-potential-child and presenting it with a child's anatomy and physiognomy, actualizing its humanity despite its liminal, dependent state. This chiastic movementwhere the actual situation is tuned toward possibility and the fetusas-potential child is rhetorically presented as an actual child-is effected through technological mediation and ekphrasis. 


\section{Conclusion: The Rhetoric of the UICA and the UICA's Rhetoric}

The UICA is a complex example of how political speech can be transformed through legislation and technologies into what Edgar characterizes as a material rhetoric (Edgar, 2017, p. 351). Through several mediators, the UICA coalesces to institute a perpetual rhetorical situation where women are subjected to a deliberation they did not ask for. The analysis moved from the gathering of actors to the actions of technologies and discourse to highlight the rhetorical techniques that antiabortion activists employ. I have argued that through political action, actors are able to secure and control environments and technologies for their own ends, they are able to accrue agency and direct its deployment. Additionally, alert readers will not have missed the phallocentric overtones of the UICA: the law is obsessed with finding a place for itself in the rhetorical opening made for it by ultrasound technology's ability to penetrate the woman's body. This ability is not metaphorical but quite literal, especially in cases where a transvaginal ultrasound may be necessary to image the anatomy and physiology of the fetus. By understanding the levels of rhetorical translations, feminist rhetoricians of science, technology, and health and medicine can continue to critique colonial technical and biomedical practices constraining women's action and surveilling their bodies and contest what Duden calls our "optical hexis" for visualizing women's bodies (Duden, 1993 p. 92; Frost \& Haas, 2017).

The preceding analysis not only serves to trace the levels of mediation that structure prenatal space, but points to ways technological mediation can alter our understanding of rhetoric. In the case of kairos, the mediational capacities of technology condition and shape situations, providing opportunities for persuasive action. The moralizing capacity of imaging technology can be seen as kairotic, recognized and harnessed by antiabortionists to institute a deliberative situation for women seeking abortion where ultrasound and medical description act as mediators of antiabortion politics. In the case of ekphrasis, imaging technologies show how different aspects of bringing forth or making present can be collapsed. Enargeia (the rhetorical power to describe and clarify) and energeia (the actualizing and vivification of discourse) are conceptually and etymologically distinct (Westin, 2017), but in the medical description the UICA mandates, the potential fetus is transformed into the actual child through a clarification and delineation of its anatomy and physiology, collapsing seeing into making (see also Daston \& Galison 2007, p. 382-412, for nanoimaging as another instance of "seeing as making"). 
The foregoing analysis has obvious limits as well. Of the more glaring is the lack of research into the reception of these types of laws and women's rhetorical tactics of confronting them. More research is needed from rhetorical studies showing "how the meanings of having an ultrasound prior to terminating a pregnancy are discursively constructed" because these accounts can "complicate dominant representations of ultrasound" (BeynonJones, 2015, pp. 694-695). Additionally, rhetorical scholars could examine the ways advocates for reproductive rights use key rhetorical concepts and techniques, such as kairos and ekphrasis, to push back against dominant and opportunistic image regimes.

During the writing of this manuscript in December 2019, the U.S. Supreme Court declined to take up a challenge to Kentucky's speech and display law, thereby allowing the law to stand and signaling to legislatures that the Supreme Court was not presently inclined to rule on such laws. Thus, these types of laws may proliferate, and exacerbate struggles for reproductive care that already disproportionally affect disadvantaged and marginalized populations, especially Black women (Roberts, [1997] 2017, p. xiv). Thus the ways reproductive rights are contested and refigured through technologies require continuous attention by rhetoric scholars of science, technology, and medicine.

Copyright (C) 2021 Scott Weedon 


\section{Reference List}

Ahmed, A. (2015). Informed decision making and abortion: crisis pregnancy centers, informed consent, and the first amendment. Journal of Law, Medicine, \& Ethics, 43(1), 51 58.

Alac, M. (2011). Handling digital brains: A laboratory study of multimodal semiotic interaction in the age of computers. Cambridge, MA: MIT Press.

Americans United for Life (2019) n.d. Retrieved from https://aul.org/what-we-do/legislation/

Barad, K. (1998). Getting real: Technoscientific practices and the materialization of reality. Differences: a journal of feminist cultural studies, 10(2), 87-91.

Beynon-Jones, S. M. (2015). Re-visioning ultrasound through women's accounts of pre-abortion care in England. Gender \& Society, 29(5), 694-715.

Booher, A. K., \& Jung, J. (Eds.). (2018). Feminist rhetorical science studies: Human bodies, posthumanist worlds. Southern Illinois University Press.

Boucher, J. (2004). Ultrasound: a window to the womb?: Obstetric ultrasound and the abortion rights debate. Journal of Medical Humanities, 25(1), 7-19.

Brownback, S. (2007). Brownback Advances Pro-Life Agenda wit Ultrasound Bill [Press Release]. Retrieved from https://votesmart.org/public statement/291887/brownback-advances-pro-life-agenda with-ultrasound-bill\&speechType $=4 \#$. Xi4 $\operatorname{cof}_{5} \mathrm{Kg} 2 \mathrm{~W}$

Callon, M. (1984). Some elements of a sociology of translation: domestication of the scallops and the fishermen of St Brieuc Bay. The sociological review, 32(1_suppl), 196-233

Casper, Monica J. (1994). At the margins of humanity: fetal positions in science and medicine. Science, technology, \& human values 19(3), 307-323.

Condit, C. M. (1990). Decoding abortion rhetoric: Communicating social change. University of Illinois Press.

Condit, C. M. (2007). How culture and science make race "genetic": Motives and strategies for discrete categorization of the continuous and heterogeneous. Literature and Medicine, 26(1), 240-268. doi:10.1353/lm.2008.0000.

Daston, L. (2016). Cloud Physiognomy. Representations, 135(1), 45 -71. https://doi.org/10.1525/rep.2016.135.1.45 
Daston, L. \& Galison, P. (2007). Objectivity. Cambridge, MA: Zone Books.

Duden, B. (1993). Disembodying women: Perspectives on pregnancy and the unborn. Harvard University Press.

Eco, U. (2004). On literature. Orlando, FL: Houghton Mifflin Harcourt.

Edgar, A. N. (2017). The rhetoric of auscultation: Corporeal sounds, mediated bodies, and abortion rights. Quarterly Journal of Speech, 103(4), 350-371.

doi.org/10.1080/00335630.2017.1360510

Fountain, T. K. (2019). Anatomical presencing: Visualization, model-making, and embodied interaction in a language-rich space.

In D. Gruber and L. Olman (eds.) The Routledge Handbook of Language and Science, pp. 227-239. New York, NY: Routledge.

Frost, E. A., \& Haas, A. M. (2017). Seeing and knowing the womb: A technofeminist reframing of fetal ultrasound toward a decolonization of our bodies. Computers and Composition, 43, 88 105. doi.org/10.1016/j.compcom.2016.11.004

Goldhill, S. (2007). What is ekphrasis for? Classical Philology, 102(1), 1-19.

Gouge, C., \& Jones, J. (2016). Wearables, wearing, and the rhetorics that attend to them. Rhetoric Society Quarterly, 46(3), 199-206. doi.org/10.1080/02773945.2016.1171689

GovTrack.us. (2020). H.R. 634 - 116th Congress: Ultrasound Informed Consent Act. Retrieved from https://www.govtrack.us/congress/bills/116/hr634

Graham, S. S. (2009). Agency and the rhetoric of medicine: Biomedical brain scans and the ontology of fibromyalgia. Technical Communication Quarterly, 18(4), 376-404.

doi.org/10.1080/10572250903149555

Gregory, R. (2012). A womb with a view: Identifying the culturally iconic fetal image in prenatal ultrasound provisions. Present Tense, 2(2).

Gross, A. G. (1990). The origin of species: Evolutionary taxonomy as an example of the rhetoric of science. In H.W. Simons (ed.) The rhetorical turn: Invention and persuasion in the conduct of inquiry, 91-115. Chicago, Il: University of Chicago Press.

Gross, A. G. (2016). The Limits of the Rhetorical Analysis of Science. Poroi, 12(1). doi 10.13008/2151-2957.1244 
Gruber, D. R. (2014). Mirror neurons in a group analysis "hall of mirrors": Translation as a rhetorical approach to neurodisciplinary writing. Technical Communication Quarterly, 23(3), 207-226. doi.org/10.1080/10572252.2013.816489

Guttmacher Institute (n.d.) Retrieved from www.guttmacher.org.

Hawhee, D. (2011). Looking into Aristotle's eyes: Toward a theory of rhetorical vision. Advances in the History of Rhetoric, 14(2), 139 -165. doi.org/10.1080/15362426.2011.613288

Haraway, D. (2004). Modest_Witness@Second_Millenium. From The Haraway Reader, 223-251. New York, NY: Routledge.

Henderson, K. (1999). On line and on paper: Visual representations, visual culture, and computer graphics in design engineering. Cambridge, MA: MIT press.

Jack, J. (2009). A pedagogy of sight: Microscopic vision in Robert Hooke's Micrographia. Quarterly Journal of Speech, 95(2), 192 -209 .

Jack, J. (2019). Raveling the brain: Toward a transdisciplinary neurorhetoric. Columbus, OH: The Ohio State University Press.

Jarratt, S. C. (2019). Chain of Gold: Greek Rhetoric in the Roman Empire. Carbondale, IL: Southern Illinois University Press.

Jordan, J. (2012). Jordan Introduces Ultrasound Informed Consent Bill. [Press Release]. Retrieved from: https://jordan.house.gov/news/documentsingle.aspx?Document $\underline{\mathrm{D}=276810}$

Joyce, K. (2005). Appealing images: Magnetic resonance imaging and the production of authoritative knowledge. Social Studies of Science, 35(3), 437-462.

Kessler, M. M., \& Graham, S. S. (2018). Terminal node problems: ANT 2.0 and prescription drug labels. Technical Communication Quarterly, 27(2), 121-136. doi.org/10.1080/10572252.2018.1425482

Kinneavy, J. L. (2002). Kairos in classical and modern rhetorical theory. In P. Sipiora and J. Baumlin (Eds.) Rhetoric and kairos: Essays in history, theory, and praxis, 58-76. Albany, NY: State University of New York Press.

Koerber, A., Booher, A. K., \& Rickly, R. J. (2012). The Concept of Choice as Phallusy: A Few Reasons Why We Could Not Agree More. Present Tense, 2(2).

Latour, B (1983). Give me a laboratory and I will raise the word. In K. Knorr-Cetina and M. Mulkay, (Eds.) Science Observed: 
Perspectives on the Social Study of Science, pp.141-170. London and Beverly Hills; Sage.

Latour, B. (1999a). Pandora's hope: essays on the reality of science studies. Cambridge, UK: Harvard university press.

Latour, B. (1999b). On recalling ANT. The sociological review, 47(1_suppl), 15-25.

Lynch, J. A., \& Kinsella, W. J. (2013). The rhetoric of technology as a rhetorical technology. Poroi, 9(1), n.d. doi10.13008/2151-

2957.1152

Manian, M. (2009). The irrational woman: Informed consent and abortion decision-making. Duke Journal of Gender Law. \& Policy, 16(2), 223-293. Available at: https://scholarship.law.duke.edu/djglp/vol16/iss2/3

Miller, C. R. (1994). Opportunity, opportunism, and progress: Kairos in the rhetoric of technology. Argumentation, 8(1), 81-96.

Mitchell, L. M. (2001). Baby's first picture: Ultrasound and the politics offetal subjects. Toronto, ON: University of Toronto Press.

Newman, K. (1996). Fetal positions: Individualism, science, visuality. Palo Alto, CA: Stanford University Press.

Paulson, M.S. (2013). A Picture Is Worth a Thousand Words: The Constitutional Soundness of Ultrasound Requirements. Public Discourse: A Journal of the Witherspoon Institute, (n.d.).

Perelman, C., \& Olbrechts-Tyteca, L. (1969). The new rhetoric: a treatise on argumentation. South Bend, IN: University of Notre Dame Press.

Petchesky, R. P. (1987). Fetal images: The power of visual culture in the politics of reproduction. Feminist studies, 13(2), 263-292.

Planned Parenthood of Southeastern Pennsylvania $v$. Casey [court case]

Poulakos, J. (1983). Toward a sophistic definition of rhetoric. Philosophy \& Rhetoric, 35-48.

Prasch, A. M. (2019). Obama in Selma: Deixis, rhetorical vision, and the "true meaning of America". Quarterly Journal of Speech, 105(1), 42-67. doi.org/10.1080/00335630.2018.1552366

Propen, A. D. (2018). Visualizing posthuman conservation in the age of the Anthropocene. Columbus, $\mathrm{OH}$ : The Ohio State University Press.

Read, S. (2016). The net work genre function. Journal of Business and Technical Communication, 30(4), 419-450. doi.org/10.1177/1050651916651909 
Rickert, T. (2013). Ambient rhetoric: The attunements of rhetorical being. Pittsburgh, PA University of Pittsburgh Press.

Rickly, R. (2007). Messy contexts: Research as a rhetorical situation. In H. McKee and D. Devoss (eds.) Messy Contexts: Research as a Rhetorical Situation, 377-397. Cresskill, NJ: Hampton Press.

Roberts, D. ([1997] 2017). Killing the black body: Race, reproduction, and the meaning of liberty, $2^{\text {nd }}$ edition. New York, NY: Vintage Books.

Roberts, W. R. (Ed.). (2011). Longinus on the Sublime: The Greek Text Edited After the Paris Manuscript. Cambridge, UK: Cambridge University Press.

Roby, C. (2016). Technical ekphrasis in Greek and Roman science and literature: The written machine between Alexandria and Rome. Cambridge, UK: Cambridge University Press.

Roundtree, A. K. (2013). Computer simulation, rhetoric, and the scientific imagination: How virtual evidence shapes science in the making and in the news. Plymouth, UK: Lexington Books.

Rowland, A. L. (2017). Zoetropes: Turning fetuses into humans at the national memorial for the unborn. Rhetoric Society Quarterly, 47(1), 26-48. doi.org/10.1080/02773945.2016.1238105

Sawicki, N. N. (2014). Compelling images: the constitutionality of emotionally persuasive health campaigns. Maryland Law Review, 73, 458-523. Available at: http://digitalcommons.law.umaryland.edu/mlr/vol73/iss2/3

Scott, J.B. \& Melonçon, L. (2018). Manifesting Methodologies for the Rhetoric of Health \& Medicine. In Melonçon, L., \& Scott, J. B. (Eds.) Methodologies for the rhetoric of health \& medicine, 1-23. New York, NY: Taylor \& Francis.

Segal, J. (2005). Health and the rhetoric of medicine. Carbondale, IL: SIU Press.

Selzer, J., \& Crowley, S. (Eds.). (1999). Rhetorical bodies. Madison, WI: University of Wisconsin Press.

Shapin, S. (1984). Pump and circumstance: Robert Boyle's literary technology. Social studies of science, 14(4), 481-520.

Stormer, N. (1997). Embodying normal miracles. Quarterly Journal of Speech, 83(2), 172-191.

Stormer, N. (2000). Prenatal space. Signs: Journal of Women in Culture and Society, 26(1), 109-144.

Stormer, N. (2008). Looking in wonder: Prenatal sublimity and the commonplace "life". Signs: Journal of Women in Culture and Society, 33(3), 647-673. https://doi.org/10.1086/523816

Weedon

Poroi 6,2 (December 2021) 
Suter, S. M. (2013). The politics of information: informed consent in abortion and end-of-life decision making. American journal of law \& medicine, 39(1), 7-61. doi.org/10.1177/009885881303900101

Talbot, J (2018). "Flat ontologies and everyday feminisms: Revisiting personhood and fetal ultrasound imaging." In A. Booher and J. Jung (Eds.) Feminist rhetorical science studies: Human bodies, posthuman worlds, 84-114. Carbondale, IL. Southern Illinois University Press.

Teston, C. (2012). Moving from artifact to action: A grounded investigation of visual displays of evidence during medical deliberations. Technical Communication Quarterly, 21(3), 187 -209. doi.org/10.1080/10572252.2012.650621

Verbeek, P. P. (2008). Obstetric ultrasound and the technological mediation of morality: A postphenomenological analysis. Human Studies, 31(1), 11-26.

Verbeek, P. P. (2011). Moralizing technology: Understanding and designing the morality of things. Chicago, IL: University of Chicago Press.

Verbeek, P. P. (2015). Toward a theory of technological mediation. In J.K. Berg, O.

Friis and Robert C. Crease (Eds.) Technoscience and Postphenomenology: The

Manhattan Papers, 189-204. London, UK: Lexington Books.

Walker, K. C. (2016). Mapping the contours of translation: Visualized un/certainties in the ozone hole controversy. Technical Communication Quarterly, 25(2), 104-120. doi.org/10.1080/10572252.2016.1149620

Walsh, L., \& Boyle, C. (Eds.). (2017). Topologies as techniques for a post-critical rhetoric. Cham, Switzerland: Palgrave Macmillan.

Webb, R. (2016). Ekphrasis, imagination and persuasion in ancient rhetorical theory and practice. New York, NY: Routledge.

Weedon, J. S. (2017). Representation in engineering practice: A case study of framing in a student design group. Technical Communication Quarterly, 26(4), 361-378. doi.org/10.1080/10572252.2017.1382258

Westin, M. (2017). Aristotle's Rhetorical Energeia: An Extended Note. Advances in the History of Rhetoric, 2O(3), 252-261. doi.org/10.1080/15362426.2017.138476 